\title{
Implementasi Citizen Public Relations Melalui Ekspresi Diri Instagram Dalam Membangun Brand Awareness Universitas Universal
}

\author{
Antoni Suparno ${ }^{1}$ \\ Universitas Universal \\ Kompleks Maha Vihara Duta Maitreya, Sei Panas, Batam, Kepulauan Riau \\ ${ }^{1}$ Email : suparno.antoni@yahoo.com
}

\begin{abstract}
ABSTRAK
Penelitian ini bertujuan untuk memahami motif para mahasiswa membuat posting ekspresi diri yang identik dengan brand Universitas Universal (UVERS), memahami bagaimana ekspresi diri para mahasiswa tersebut membangun brand awareness Universitas Universal (UVERS), dan alasan para mahasiswa memilih Instagram untuk melakukan ekspresi diri. Penelitian kualitatif ini menggunakan metode Kualitatif Deskriptif dengan menerapkan teknik pengumpulan data focus group discussion (FGD), teknik wawancara, observasi, hingga pengumpulan data dokumen, visual, dan audio. Temuan yang didapatkan melalui penelitian ini adalah para mahasiswa memiliki motif untuk memperkenalkan kegiatan dan nilai-nilai Universitas Universal (UVERS) di setiap ekspresi dirinya di Instagram. Sedangkan brand awareness Universitas Universal (UVERS) dapat terbentuk dengan SoMe storytelling branding atau Citizen Public Relations yang dilakukan oleh para mahasiswa. Kemudian para mahasiswa juga tertarik menggunakan Instagram karena kelebihan Instagram untuk surveillance, documentation, creativity, dan coolness.
\end{abstract}

Kata Kunci : Motif, Brand Awareness, SoMe Storytelling Branding, Citizen Public Relations.

\begin{abstract}
This study aims to understand the motives of students to post self expression that is identic to the Universal University (UVERS) brand, understanding how the student self expression builds Universal University (UVERS) brand awareness, and their reason chose Instagram to do self expression. This qualitative research uses descriptive qualitative method by applying focus group disscussion (FGD) data collection techniques, interview techniques, observation, and collecting document, visual, and audio data. The findings obtained through this study are that students have a motive to introduce the Universal University (UVERS) activities and values in each expression of themselves on Instagram. While, Universal University (UVERS) brand awareness can be formed with SoMe storytelling branding or Citizen Public Relations conducted by students. Then the students are also interested in using Instagram because of the advantages of Instagram for surveillance, documentation, creativity, and coolness.
\end{abstract}

Keywords : Motives, Brand Awareness, SoMe Storytelling Branding, Citizen Public Relations. 


\section{PENDAHULUAN}

Pengguna internet di Indonesia terus bertumbuh setiap tahun, bahkan lembaga riset pasar e-Marketer memperkirakan jumlah pengguna internet di Indonesia pada tahun 2017 akan mencapai angka 112 juta jiwa (Yusuf, 2014). Hal tersebut tentu tidak dapat dilepaskan dari peran perkembangan teknologi internet yang semakin cepat.

Pada tahun 2017, temuan dalam survey yang dilakukan oleh Asosiasi Penyedia Jasa Internet Indonesia (APJII) menemukan fakta baru terkait penggunaan internet di Indonesia. Pengguna internet di Indonesia pada tahun 2017 menyentuh angka 143,26 juta jiwa. Angka tersebut meningkat dari tahun sebelumnya yang hanya mencatat pengguna internet di Indonesia sebanyak 132,7 juta jiwa. Pengguna internet pada tingkat pendidikan SMA atau sederajat bahkan mencapai 70,54\% pada tahun tersebut (Kompas.com, 2018). Fakta tersebut menunjukkan bahwa kesadaran masyarakat Indonesia untuk menggunakan internet dalam kesehariannya juga semakin meningkat, bisa dikatakan internet telah menjadi salah satu keharusan dalam kehidupan seorang manusia.

Dari fakta tersebut dapat juga dilihat bahwa, pengguna internet di Indonesia didominasi oleh masyarakat umur 18-25 tahun yang biasanya sedang menempuh pendidikan menengah atas hingga perguruan tinggi. Siswa dan mahasiswa dapat dikatakan sebagai pengguna internet yang paling banyak di indonesia. Artinya, para siswa sekolah telah sangat lekat dengan kebiasaan berinternet, sehingga internet telah menjadi salah satu lingkungan baru tempat mereka hidup dan berinteraksi.

Survei juga menyebutkan bahwa Facebook, Instagram, dan Youtube menjadi 3 media sosial yang paling disukai oleh para pengguna internet (Hidayat, 2016). Dengan angka 71,6 juta jiwa pengguna Facebook, 19,9 juta jiwa pengguna instagram, dan 14,5 juta jiwa pengguna Youtube, sekaligus menegaskan bahwa jejaring sosial adalah bagian hidup yang sangat penting bagi para pengguna internet. Penelitian ini akan berfokus pada Instagram sebagai salah satu media sosial yang sering digunakan oleh millennials.

Dari berbagai hal dan gambar yang muncul dalam akun Instagram seseorang memiliki banyak arti. Bahkan salah satu penelitian menyebutkan bahwa tumpang tindih sering terjadi antara merek komunitas dan media sosial. Keterlibatan sebuah komunitas dalam media sosial akan memperkuat hubungannya dengan masyarakat, pada akhirnya hubungan yang terbangun itu akan berimplikasi pada kepercayaan pada merek (Habibi, Laroche, \& Richard, 2014). Kepercayaan pada merek komunitas tersebut semakin dapat diwujudkan karena media sosial kini memperoleh kepercayaan sebagai sumber 
pengetahuan dan informasi yang lebih tinggi dibandingkan promosi tradisional di televisi maupun media lainnya (Kesavan, Bernacchi, \& Mascarenhas, 2013).

Lebih jauh, komunikasi melalui internet juga digambarkan sebagai "second life" karena setiap kegiatan yang dilakukan di dalamnya telah menjadi "everyday life" bagi banyak orang termasuk anak-anak muda (Konijn, Utz, Tanis, \& Barnes, 2008). Penggunaan internet dan sosial media sebagai second life juga terjadi pada para mahasiswa Universitas Universal (UVERS). Hampir semua kegiatan yang dilakukan oleh para mahasiswa dalam kehidupan sehari-hari mereka dibagikan melalui sosial media. Kegiatan-kegiatan mereka di kampus juga menjadi salah satu kegiatan yang dibagikan kepada khalayak dunia maya. Para mahasiswa seringkali menyertakan caption, foto, petunjuk lokasi, dan berbagai hal yang berhubungan dengan Universitas Universal (UVERS). Terlebih, para mahasiswa juga sering berfoto dengan mengenakan almamater khas Universitas Universal (UVERS), hal ini tentu memperkuat identitas mereka sebagai mahasiswa Universitas Universal (UVERS). Para mahasiswa tentu juga memiliki motif dan tujuannya sendiri ketika membagikan foto-foto yang identik dengan identitas Universitas Universal (UVERS). Motif tersebut tentu akan menjadi hal yang menarik untuk dikaji.
Penelitian ini pada akhirnya bertujuan untuk memahami motif para mahasiswa melakukan ekspresi diri di Instagram yang identik dengan brand Universitas Universal (UVERS), memahami bagaimana ekspresi diri tersebut membangun brand awareness Universitas Universal (UVERS), dan mengapa para mahasiswa tertarik menggunakan Instagram dalam melakukan ekspresi diri.

Pembahasan tentang motif para mahasiswa akan dilihat melalui teori yang dikemukakan oleh Kenneth Burke, Grammar of Motives yang akan memberikan penjelasan tentang apa yang dilakukan oleh seseorang dan mengapa ia melakukan hal itu (Burke, 1962). Sesungguhnya Grammar of Motives berkaitan erat dengan Dramatism Theory, sebab kedua teori ini dikemukakan oleh Burke. Manusia disebutkan hidup dalam dunia drama simbol, simbol dan bahasa yang digunakan adalah hasil dari respon dan motivasi atas sebuah stimulus (Littlejohn \& Foss, 2009). Dramatism Theory yang juga dicetuskan oleh Kenneth Burke, ia membayangkan kehidupan seperti sebuah permainan dan cuplikan teater, untuk itu kita membutuhkan aktor (agent), adegan (act), tempat berlangsungnya adegan (scene), dan beberapa konteks yang mendukung terjadinya sebuah adegan (agency), hingga tujuan dari adegan itu (purpose) (West \& Turner, 2010). 
Kegiatan ekspresi diri para mahasiswa di Instagram akhirnya dapat dilihat sebagai branding yang dilakukan secara tanpa disadari. Masyarakat kini semakin banyak menghabiskan waktunya di dalam internet, bahkan Lang mengatakan bahwa rata-rata pengguna internet menghabiskan sepertiga waktunya setiap hari untuk konsumsi media sosial. Dikarenakan media sosial yang semakin populer, banyak perusahaan yang memperkenalkan dirinya melalui media sosial (Laroche, Habibi, \& Richard, 2013). Salah satu brand yang perlu memperkenalkan dirinya melalui media sosial adalah Universitas Universal (UVERS). Demi mendukung munculnya online word of mouth melalui social media branding, Luttrell (2015) memperkenalkan sebuah konsep yang disebut The Circular Model of SoMe for Social Communication. Konsep dan model social communication SoMe terdiri dari Share, Optimize, Manage, dan Engage.

Para mahasiswa menceritakan kesehariannya melalui ekspresi diri yang identik dengan brand Universitas Universal (UVERS) melalui Instagram. Kegiatan menceritakan keseharian tersebut dapat pula disebut sebagai digital storytelling. Alexander (2011) dengan sederhana menyebutkan bahwa digital storytelling adalah "telling stories with digital technologies” (p.3). Artinya menceritakan sebuah cerita dengan teknologi digital.

$$
\text { Hartley dan McWilliam (2009) }
$$
menyatakan bahwa pada masa mendatang kita akan dikenalkan dengan istilah story circle. Pada tahapan ini yang menjadi fokus bukan hanya tentang keahlian seseorang dalam bernarasi, namun juga tentang bagaimana mereka membagikan gagasan dan ceritanya secara spontan serta melebur dalam salah satu kegiatan di kehidupan sehari-hari (pp.3-4). Jadi, untuk membagikan sebuah cerita bukan lagi menjadi sebuah perencanaan yang harus dilakukan dalam jangka panjang, tapi sebuah kegiatan spontan yang dilakukan dengan cepat. Walter dan Gioglio (2014) bahkan memperkenalkan istilah visual storytelling yang didefinisikan sebagai penggunaan gambar, video, infografik, presentasi, dan visual lainnya di sosial media untuk menciptakan cerita tentang pesan kunci sebuah brand (p.8).

Visual storytelling akhirnya dipraktekkan oleh para mahasiswa melalui Instagram. Saat ini, Instagram masih menjadi salah satu new media yang berkembang paling cepat dibanding platform lainnya (Sheldon \& Bryant, 2016). Pertumbuhan yang demikian cepat menunjukkan bahwa new media berbasis foto kini lebih disukai dibandingkan jenisjenis lainnya. Oleh karena pertumbuhannya yang cepat, kita perlu memahami apa 
bentuk konten yang membuat para pengguna Instagram merasa terhubung (Bakhshi, Shamma, \& Gilbert, 2014).

Dari penelitian yang dilakukan oleh Sheldon \& Bryant (2016), terdapat 4 motif seseorang dalam menggunakan Instagram, yaitu surveillance/knowledge about other (mengetahui tentang orang lain), documentation (dokumentasi aktivitas), creativity (berbagi kreativitas), dan coolness (keren). Penelitian menunjukkan bahwa alasan terkuat seseorang menggunakan Instagram adalah untuk alasan surveillance/knowledge about other atau pengetahuan tentang orang lain. Artinya melihat aktivitas yang dilakukan oleh orang lain menjadi alasan yang sangat penting bagi seseorang ketika ia memutuskan untuk menggunakan Instagram.

\section{METODE PENELITIAN}

Penelitian ini menggunakan metode kualitatif deskriptif. Penelitian kualitatif dengan pendekatan deskriptif dilakukan untuk memberikan deskripsi atas gejala, peristiwa, dan kejadian aktual yang sedang berlangsung (Nofriansyah, 2018). Dengan kata lain, penelitian kualitatif deskriptif akan berupaya untuk menjelaskan sebuah fenomena yang sedang terjadi di dalam masyarakat. Whitney (dalam Prihartono, 2016) menjelaskan bahwa kualitatif deskriptif dilakukan dengan menggunakan interpretasi yang tepat dalam menemukan fakta. Fakta-fakta akurat tersebut yang kemudian akan digambarkan menjadi deskripsi tentang keterkaitan antar fenomena yang sedang diteliti.

$$
\text { Kualitatif deskriptif biasanya }
$$

diterapkan dalam penelitian yang belum memiliki metode yang ditentukan secara jelas ataupun penelitian yang diakhiri dengan penjelasan yang sangat komprehensif tentang sebuah peristiwa dan kejadian (Grove, Burns, \& Gray, 2013). Pada akhirnya, metode ini dapat digunakan untuk menjawab sebuah fenomena yang tidak memiliki metode yang tepat karena dijelaskan dalam kajian yang sangat luas. Penelitian ini juga melakukan pengambilan data dengan Focus Group Disscussion (FGD), Observasi, dan Penelusuran Dokumen, Audio, dan Visual.

\section{HASIL DAN PEMBAHASAN}

Act and Agent (SoMe Storytelling Branding oleh Mahasiswa)

Marty Neumeier (dalam Chritton, 2012) juga mengungkapkan 3 alasan branding sangat penting untuk dilakukan. Pertama, masyarakat terlalu banyak pilihan dengan waktu memilih yang singkat; Kedua, kualitas dan fitur yang ditawarkan boleh dikatakan mirip; dan Ketiga, pada akhirnya masyarakat membuat keputusan berdasarkan rasa percaya. Pernyataan Neumeier tersebut terasa semakin nyata saat ini, Indonesia telah memiliki sangat 
banyak perguruan tinggi dengan penawaran fitur yang sama, sedangkan masyarakat tidak memiliki banyak waktu untuk memilih, memunculkan rasa percaya pada brand perguruan tinggi adalah salah satu hal terbaik yang dapat dilakukan. Pada akhirnya untuk mendapatkan rasa percaya tersebut, brand harus muncul dan hidup di dalam benak konsumen, termasuk konsumen millennial.

"Supaya brand itu hidup, berbicara tentang generasi millennial, kalau lu mau hidup ya lu harus masuk ke dalam dunianya dia." (Haris Suhendra, Wawancara, 4 Agustus 2018)

Setelah berhasil masuk dan hidup di dalam kehidupan masyarakat, barulah sebuah brand dapat meraih kepercayaan masyarakat yang menjadi permulaan dari sebuah brand yang dipilih oleh masyarakat, bahkan brand yang melebur bersama kesehariannya.

Dengan dorongan kemajuan teknologi, kini brand memiliki trend baru untuk melebur ke dalam kehidupan khalayaknya. Brand bahkan lebih banyak melakukan kegiatan branding di sosial media, karena masyarakat kini lebih sering menghabiskan waktunya untuk konsumsi media sosial (Laroche, Habibi, \& Richard, 2013). Pada akhirnya, Universitas Universal (UVERS) juga mulai melaukan branding di media sosial. Haris Suhendra menyatakan bahwa hal ini adalah sebuah keharusan yang didorong oleh karakter masyarakat yang lebih millennial.

Dari hasil penelusuran data online juga menunjukkan bahwa trend masyarakat untuk melakukan aktivitasnya di dunia maya semakin meningkat. Dari populasi masyarakat Indonesia sekitar 265.000.000 jiwa, pengguna internet aktif terhitung sekitar 132.000.000 jiwa, dengan pengguna media sosial aktif sekitar 130.000.000 jiwa, data juga menunjukkan terdapat kenaikan jumlah pengguna media sosial di Indonesia sebesar 23\% (Hootsuite, 2018). Dengan fakta tersebut, tentu tidak mengherankan jika kini banyak brand yang melakukan branding melalui media sosial.

Artinya, tidak ada pilihan lain bagi brand, termasuk brand Universitas Universal (UVERS), selain masuk dan melebur bersama khalayak atau masyarakat di media sosial. Tidak lain untuk memahami kebutuhan dan menciptakan kebutuhan bagi masyarakat. Namun yang menjadi menarik dalam kajian ini adalah branding bagi Universitas Universal (UVERS) tidak hanya dilakukannya sendiri, namun juga dilakukan oleh para mahasiswanya, meski para mahasiswa tidak menyadari yang mereka lakukan adalah kegiatan branding. Haris Suhendra berpendapat para mahasiswa menganggap brand Universitas Universal (UVERS) 
sebagai salah satu bagian hidupnya yang perlu diekspresikan.

"Branding kan sebenarnya istilah yang dipakai oleh orang marketing, tapi buat costumer atau mahasiswa itu sendiri kan dia tidak masuk dalam ruang lingkup dia harus melakukan branding, dia hanya mengekspresikan apa yang dia ekspresikan dalam hal ini di kampus, dia ingin mengatakan bahwa ini kampus gue loh keren...yang pasti yang diharapkan bukan branding-nya, tapi yang diharapkan orang memberikan feedback bahwa oh kampus lu keren ya" (Haris Suhendra, Wawancara, 4 Agustus 2018).

Setelah melakukan ekspresi terkait dengan brand Universitas Universal (UVERS) para mahasiswa hanya mengharapkan para follower-nya untuk memberikan feedback dan pengakuan pada kampusnya, namun mereka tidak menyadari hal tersebut adalah bagian dari kegiatan branding. Para mahasiswa hanya tertarik untuk menceritakan hal-hal yang ada di dalam kesehariannya. Marni Octavia dan Jeri Gunawan mengungkapkan bahwa mereka seringkali tertarik untuk membicarakan tentang kegiatan-kegiatan perkuliahan di Universitas Universal (UVERS) agar pihak lain menyadari eksistensi kampus tersebut.
Oleh karena pergeseran trend dan perubahan perilaku khalayak tersebut, praktik para mahasiswa dalam melakukan ekspresi yang identik dengan brand Universitas Universal (UVERS) adalah sebuah keniscayaan serta dorongan zaman. Para mahasiswa bukan lagi membicarakan tentang brand, namun mereka mengajak brand untuk menyatu dengan bagian hidupnya (Salter, 2012), Universitas Universal (UVERS) menjadi sebuah entitas yang menyatu dan berinteraksi dengan khalayak melalui identitas para mahasiswanya. Pada akhirnya, pernyataan Salter (2012) bahwa "online puts public back into public relations" menjadi relevan. Branding tidak hanya memberikan pengaruh kepada publik, namun branding ditujukan untuk membangun hubungan. Peran dalam membangun hubungan interpersonal dan mengintegrasikan brand Universitas Universal (UVERS) menjadi peran ganda bagi para mahasiswa. Di satu sisi, mereka perlu membangun hubungan, di sisi lain secara tidak sadar menjelma sebagai public relations bagi brand Universitas Universal (UVERS).

Berbicara soal social media branding maka kita akan membicarakan tentang word of mouth yang berhasil dimunculkan. Para mahasiswa yang membicarakan tentang brand Universitas Universal (UVERS) juga secara tidak langsung memunculkan word of mouth. Luttrel (2015) memperkenalkan 
sebuah konsep sebuah strategi social media branding, yaitu SoMe. SoMe akan menuntun kita untuk menjalankan kegiatan social media branding untuk era perkembangan teknologi yang semakin pesat. Penjelasan tentang konsep SoMe yang terdiri dari Share, Optimize, Manage, dan Engage adalah sebagai berikut (Luttrell, 2015) :

1. Share : Kemampuan media sosial dalam menghubungkan orangorang yang memiliki kedekatan dan kesamaan adalah sebuah keunggulan yang patut untuk diakui. Terlebih dengan kemampuannya untuk membangun hubungan interpersonal terlebih dahulu sebelum seseorang membicarakan tentang brand yang ia rekomendasikan kepada pihak lain. Sebenarnya, apapun yang dilakukan oleh para mahasiswa Universitas Universal (UVERS) di media sosial adalah sebuah kebiasaan sehari-hari yang lumrah. sehingga ketika para mahasiswa membicarakan tentang brand Universitas Universal (UVERS) itu dianggap sebagai sebuah ekspresi, bukan kegiatan branding untuk memperkenalkan sebuah brand

2. Optimize : Media sosial mampu mengoptimalkan pesan yang ingin disampaikan oleh sebuah brand dengan cara masuk ke dalam kehidupan khalayak untuk mendengar dan berkomunikasi tentang brand. Para mahasiswa juga secara tidak langsung telah melakukan konsep optimize ketika mereka membuat posting terkait dengan brand Universitas Universal (UVERS). Para mahasiswa secara sukarela membicarakan brand Universitas Universal (UVERS) secara terbuka kepada khalayak sebagai bagian dari ekspresinya.

3. Manage : Pembicaraan di media sosial terjadi dengan cepat, sehingga brand juga harus mampu membuat respon yang cepat terkait dengan pembicaraan tersebut. Dari observasi yang dilakukan, Universitas Universal (UVERS) adalah sebuah perguruan tinggi di Kota Batam yang memiliki peraturan kehidupan kampus yang sangat ketat. Bahkan untuk sekedar mewarnai rambut dan mengenakan pakaian jenis kaos tidak diperkenankan. Sehingga pihak eksternal sering menganggap Universitas Universal (UVERS) adalah perguruan tinggi yang tidak menyenangkan dan kaku. Namun para mahasiswa tidak berpikir hal 
itu sebagai sebuah kekurangan, justru mereka menanggapi hal ini sebagai hal positif. Ketika ditanya pendapatnya dalam FGD, seluruh mahasiswa menyebutkan peraturan yang ketat sebagai salah satu nilai yang mereka anggap sebagai pembeda.

4. Engage : Brand harus selalu terhubung dengan khalayak, oleh sebab itu brand harus masuk ke dalam platform yang paling banyak dihuni oleh khalayaknya. Brand Universitas Universal (UVERS) telah hidup dan terhubung dengan khalayaknya melalui para mahasiswa. Haris Suhendra menyebutkan bahwa para mahasiswa sesungguhnya hanya melakukan dokumentasi keseharian, ekspresi diri, membangun profil, dan menunjukkan status. Kebetulan keseharian, ekspresi, profil, dan statusnya berkaitan erat dengan Universitas Universal (UVERS), mereka hanya berharap pengakuan dari khalayak tentang eksistensi diri dan kampusnya.

Sesungguhnya, kegiatan membicarakan brand Universitas Universal (UVERS) yang dilakukan oleh para mahasiswa di Instagram tepat disebut sebagai digital storytelling. Digital storytelling disebut oleh Alexander sebagai "telling stories with digital technologies" (p.3). Para mahasiswa juga menyampaikan cerita-cerita tentang brand Universitas Universal (UVERS) melalui teknologi digital new media khususnya Instagram.

Para mahasiswa sebenarnya sedang membagikan kisah-kisah pendek yang terjadi dalam hidupnya melalui media digital (Hartley \& McWilliam, 2009) dengan tujuannya masing-masing (Alexander, 2011). Berbagai kisah pendek diceritakan oleh para mahasiswa melalui Instagramnya setiap hari yang kebetulan identik dengan brand Universitas Universal (UVERS).

Kini kita telah tiba di era yang disebut oleh Hartley dan McWilliam (2009) sebagai story circle, dimana khalayak membagikan gagasannya secara spontan dan melebur bersama kesehariannya. Artinya saat ini gagasan tidak disampaikan secara khusus, namun gagasan tersebut telah tergambar dalam keseharian yang disampaikan di dalam sebuah cerita. Banyaknya kisah dan cerita tentang kebersamaan oleh para mahasiswa adalah sebuah spontanitas yang gagasannya adalah menunjukkan bahwa Universitas Universal

(UVERS) berlandaskan nilai-nilai peradaban dunia satu keluarga.

Disini dapat dilihat bahwa para mahasiswa yang membicarakan tentang brand Universitas Universal (UVERS) 
telah dapat menjadi agen-agen social media branding tanpa mereka sadari. Pada akhirnya muncul pandangan bahwa menggunakan bagian-bagian dari khalayak untuk mengomunikasikan brand menjadi hal yang krusial. Oleh sebab, Haris Suhendra menyebutkan bahwa jika sebuah brand ingin eksis maka harus berhasil masuk ke dalam benak, keseharian, dan dunianya khalayak. Brand Universitas Universal (UVERS) melakukannya dengan masuk dalam keseharian para mahasiswanya untuk dikomunikasikan sebagai bentuk ekspresi.

\section{Scene and Agency (Instagram in Frame of} CMC)

Computer mediated communication dan cyberspace memungkinkan khalayak untuk melakukan kegiatan-kegiatan konvensional (Mooij, 2014), tidak hanya itu, manusia juga dimungkinkan untuk berkomunikasi jarak jauh meskipun terpisah oleh jarak (Schummer \& Lukosch, 2007). Haris Suhendra bahkan menyebutkan bahwa tidak hanya berkomunkasi, para millennials saat ini juga melakukan hal-hal lain di dalam dunia internet, yaitu melakukan dokumentasi, mengekspresikan diri, membangun profil, hingga menunjukkan status. Artinya banyak hal yang dulu dilakukan secara langsung kini berpindah ke kehidupan di dunia maya, dapat pula disebut second life bagi manusia yang kedudukannya sama dengan dunia nyata.

Penelusuran data online semakin membuktikan bahwa cyberspace memiliki kedudukan yang sama dengan dunia nyata. Data menunjukkan bahwa dengan total populasi Indonesia sekitar 265.000.000 jiwa, masyarakat Indonesia yang aktif menggunakan internet adalah sekitar 132.000.000 jiwa (Hootsuite, 2018). Artinya 50\% dari total populasi masyarakat Indonesia adalah pengguna aktif internet. Hal itu ditambah lagi dengan fakta bahwa masyarakat Indonesia menghabiskan sekitar 8 jam dan 51 menit untuk berselancar di dunia maya (Hootsuite, 2018). Fakta tersebut menunjukkan kerelaan masyarakat menghabiskan waktu di dunia maya dengan waktu yang panjang, namun tetap melakukan interaksi dengan manusia lainnya.

Sesuai dengan kajian dalam penelitian ini, para mahasiswa Universitas Universal (UVERS) cenderung lebih sering menggunakan media sosial Instagram dalam berinteraksi di cyberspace. Jika cyberspace dan computer mediated communication adalah scene dalam setting ini, maka Instagram akan menjadi agency. Instagram merupakan bagian atau salah satu jenis new media yang sedang eksis saat ini.

Salah satu new media yang paling sering digunakan oleh khalayak saat ini ialah Instagram. Sebab Instagram 
memfasilitas khalayak bagi khalayak untuk berkomunikasi lewat foto dan gambar yang mereka bagikan, wajah dipercaya sebagai salah satu instrumen komunikasi nonverbal yang paling kuat. Hal tersebut disebabkan karena wajah seringkali dapat memberikan informasi penting tentang seseorang (Bakhshi, Shamma, \& Gilbert, 2014).

Data yang ditemukan dengan penelusuran online menyebutkan bahwa hingga saat ini pengguna aktif Instagram adalah sekitar 53.000.000 orang, atau sekitar 20\% dari total populasi masyarakat Indonesia (Hootsuite, 2018). Dengan menggunakan konten foto, Instagram terus mendapatkan sambutan dari para millennials. Marni Octavia dan Susanti berpendapat bahwa konten Instagram yang berbentuk foto dapat memungkinkan ekspresi yang ditampilkan semakin nyata dan terasa. Belinda Ivana Lira menyebutkan bahwa foto yang diunggah di Instagram justru akan berbicara lebih banyak dibanding caption yang ditulis.

Tidak hanya itu, penggunaan Instagram sebagai platform berbasis foto juga terbukti dapat menurunkan tingkat kesepian yang telah menjadi masalah serius di kalangan millennials (Pittman \& Reich, 2016). Dengan ekspresi dan moment yang terasa lebih nyata seperti disebutkan sebelumnya, maka tidak aneh jika Jenny D berpendapat bahwa ia merasa mendapatkan lebih banyak perhatian di Instagram, oleh sebab orang lain dapat merasakan dan berempati atas apa yang sedang ia rasakan.

Dengan alasan-alasan tersebut, maka penelitian yang dilakukan oleh Ting menjadi masuk akal. Penelitian tersebut mengungkapkan bahwa kaum millennials di Hongkong menggunakan Instagram setiap hari, semakin banyak teman maka mereka akan menghabiskan waktu yang lebih panjang di Instagram (Ting, 2014). Namun, secara lebih spesifik Sheldon dan Bryant menyebutkan 4 motif utama seseorang menggunakan Instagram dalam kesehariannya (Sheldon \& Bryant, 2016), yaitu :

1. Surveillance/knowledge about other : Para pengguna Instagram ingin mengetahui hal-hal terkait dengan orang lain. Hal ini juga terjadi pada para mahasiswa Universitas Universal (UVERS). Misalnya untuk melihat foto dan insta story teman hingga melakukan stalking untuk mengetahui keseharian orang lain.

2. Documentation : Tidak hanya ingin melihat aktivitas dan keseharian pihak lain, para pengguna Instagram juga tertarik untuk mendokumentasi aktivitas sehari-hari yang mereka jalani dalam bentuk foto, insta story, atau bahkan live video. Aktivitas yang didokumentasikan juga beragam, 
mulai dari kegiatan-kegiatan kampus, kebersamaan bersama teman, dan hal-hal lainnya.

3. Creativity : Instagram juga digunakan untuk menunjukkan kreativitas oleh para penggunanya. Marni Octavia adalah salah satu mahasiswa Universitas Universal (UVERS) yang menggunakan Instagram secara kreatif. Ia mengungkapkan bahwa foto yang akan diunggah berikutnya sangat bergantung pada tema-tema pada foto sebelumnya, ia akan menyesuaikan warna foto, cerita yang ada di foto, caption, dan halhal lainnya. Marni Octavia melakukannya dengan tujuan agar Instagramnya tertata dengan rapi dan menarik untuk dilihat. Selain itu, Belinda Ivana Lira juga memanfaatkan Instagram dengan kreatif. Ia mengaku seringkali membuat live video melalui Instagram, namun ia seringkali membuat live video dengan tematema tertentu, misalnya menyanyi, bercerita, atau hal lainnya. Belinda mengungkapkan jika membuat live video dengan tema yang jelas maka penonton akan lebih banyak.

4. Coolness : Para pengguna Instagram merasa Instagram adalah salah satu media sosial yang keren saat ini. Tentu Instagram menjadi begitu digemari bukan hanya karena Instagram menyediakan konten-konten foto, namun juga fitur-fiturnya yang menarik. Susanti mengaku tertarik menggunakan Instagram karena banyak teman yang menggunakan, selain itu konten dan informasi di Instagram juga menarik. Marni Octavia dan Jenny D menyebutkan bahwa Instagram juga memiliki fitur dan konten yang sangat update. Sehingga seperti yang disampaikan oleh Jeki, dengan hanya melihat Instagram, orang lain telah dapat mengetahui dimana ia berada dan apa yang sedang ia lakukan.

\section{Purpose (Building Brand Awareness)}

Berbicara soal purpose atau tujuan dari rangkaian ekspresi diri para mahasiswa yang identik dengan brand Universitas Universal (UVERS) maka pembicaraan akan berlanjut kepada output yang dihasilkan dari proses tersebut. Disadari atau tidak oleh para mahasiswa, ekspresi diri yang mereka lakukan berpotensi untuk meningkatkan brand awareness Universitas Universal (UVERS). Beragam tujuan sebenarnya melatarbelakangi ekspresi diri para mahasiswa yang terkait dengan Universitas Universal (UVERS). Marni 
Octavia menyebutkan bahwa ia melakukan hal tersebut dengan tujuan agar khalayak mengetahui proses-proses belajar di Universitas Universal (UVERS). Selain itu, Jeri Gunawan bertujuan untuk menunjukkan eksistensi program studinya, yaitu program studi Teknik Industri, dengan demikian program studi tempatnya belajar akan semakin dikenal oleh khalayak.

Jeki mengaku melakukan ekspresi diri identik dengan Universitas Universal (UVERS) dengan tujuan untuk memperkenalkan kampusnya kepada pihak luar. Secara lebih spesifik, Verlyn Yulia pernah tertarik untuk membicarakan kegiatan-kegiatan mahasiswa di UMKM (Usaha Mikro, Kecil, dan Menengah) Center, demi menunjukkan bahwa kegiatan UMKM berjalan dengan baik di Universitas Universal (UVERS). Lebih jauh, Jenny D bertujuan untuk memperkenakan Universitas Universal (UVERS) sebagai tempat kuliah yang menyenangkan dengan nilai-nilai peradaban dunia satu keluarga yang telah menjadi ciri khas. Ia berharap dengan membuat posting tersebut, maka khalayak akan tertarik atau penasaran untuk mencari tahu tentang brand Universitas Universal (UVERS). Susanti bahkan secara tegas menyatakan bahwa ia melakukan hal tersebut untuk mempromosikan Universitas Universal (UVERS) kepada khalayak. Selain menunjukkan eksistensi brand Universitas Universal (UVERS), para mahasiswa juga berusaha untuk menunjukkan keunikan-keunikan yang dimiliki oleh Universitas Universal (UVERS), yaitu memiliki nilai-nilai peradaban dunia satu keluarga dan peraturan yang sangat disiplin.

Brand awareness berperan penting dalam perjalanan sebuah brand, oleh sebab khalayak akan menentukan keputusan memilih brand setelah menyadari kehadiran dan keunikan sebuah brand (Malik, et al., 2013). Oleh karena itu, bagaimanapun brand awareness harus dibangun sejak dini, dan brand awareness Universitas Universal (UVERS) secara tidak langsung dibangun melalui ekspresi diri mahasiswanya. Haris Suhendra juga menyebutkan bahwa ekspresi diri mahasiswa dapat dimanfaatkan untuk membangun brand awareness, salah satu caranya adalah dengan mendorong mahasiswa untuk berekspresi tentang brand Universitas Universal (UVERS).

Jika brand awareness telah tertanam dengan baik pada brand Universitas Universal (UVERS), maka khalayak akan berpikir tentang brand Universitas Universal (UVERS) ketika berpikir tentang perguruan tinggi di Indonesia maupun di Kota Batam. Tidak hanya terlintas sebagai salah satu brand dalam kategori perguruan tinggi, dengan adanya brand awareness khalayak akan mulai menjadikan brand Universitas Universal (UVERS) sebagai pertimbangan dalam membuat keputusan 
memilih brand (Barreda, Nusair, Bilgihan, \& Okumus, 2013).

Dengan perkembangan media sosial yang semakin maju, publik kini dapat ikut serta dalam mengembangkan brand awareness perusahaan (Barreda, Bilgihan, Nusair, \& Okumus, 2015). Hal ini benarbenar terbukti saat ini, dari observasi yang dilakukan, para mahasiswa terlibat dalam mengembangkan brand awareness Universitas Universal (UVERS) melalui ekspresi diri mereka di Instagram. Oleh karena itu, saat ini Universitas Universal (UVERS) tidak lagi melakukan pengembangan brand awareness sendiri, namun juga dibantu oleh para mahasiswa.

Kehadiran brand di dunia maya saat ini sangat dibutuhkan, brand bersentuhan langsung dengan khalayak sambil membangun kepercayaan khalayak pada brand (Cawsey \& Rowley, 2016). Namun hal yang menjadi kesulitan dalam hal ini adalah perusahaan yang semakin sulit menyembunyikan motif komersilnya ketika berhadapan dengan publik (Limkangvanmongkol, 2015). Oleh karena itu, salah satu cara adalah menggunakan publik internal untuk melakukan branding (Rokka, Karlsson, \& Tienari, 2013).

Meskipun Universitas Universal (UVERS) adalah sebuah brand perguruan tinggi, namun motif komersialnya juga sulit untuk disembunyikan dari publik. Pada akhirnya Universitas Universal (UVERS) membangun kepercayaan khalayak melalui ekspresi diri para mahasiswanya.

\section{New PR : Citizen Public Relations}

Saat ini, brand semakin sulit untuk menyembunyikan atau menutupi motivasi komersilnya (Limkangvanmongkol, 2015) meskipun brand melakukan kegiatan public relations. Seperti yang disampaikan sebelumnya, keterkaitan langsung antara public relations dan brand percaya atau tidak menyulitkan langkah public relations dalam menjalankan fungsinya.

Saat ini, brand dimudahkan dengan kehadiran media sosial. Media sosial memungkinkan perusahaan untuk terhubung langsung dengan khalayaknya (Tsimonis \& Dimitriadis, 2014). Akhirnya, banyak brand yang mulai menggunakan media sosial agar semakin dekat dengan khalayak. Haris Suhendra menyebutkan bahwa pergeseran trend, perubahan karakteristik industri, perubahan perilaku khalayak, akhirnya memaksa brand untuk hidup bersama khalayak di dunia maya. Bahkan hal ini telah menjadi sebuah keharusan, bukan lagi hal yang aneh.

Perkembangan internet tidak hanya menyebabkan public relations membuat perpanjangan tangan di dunia maya, namun juga melahirkan trend baru dalam dunia public relations yang disebut oleh Limkangvanmongkol sebagai Post Post Modern Branding Paradigm. Post Post 
Modern Branding Paradigm adalah paradigma branding yang menjadikan khalayak brand sebagai artis untuk mempromosikan brand, khalayak tidak akan terbeban oleh pesan persuasi oleh karena brand telah menyatu dengan kehidupannya (Limkangvanmongkol, 2015).

Post Post Modern Branding Paradigm inilah yang diterjemahkan lebih lanjut sebagai Citizen Public Relations. Post Post Modern Branding Paradigm atau Citizen Public Relations akan menggunakan publik internal brand untuk melakukan branding, oleh sebab di mata kolega, keluarga, dan follower-follower publik internal sebuah brand tidak dipandang sebagai entitas yang terkait langsung dengan brand, mereka tetap dipandang sebagai bagian dari masyarakat sehingga rekomendasinya atas sebuah brand tidak dianggap sebagai upaya promosi (Rokka, Karlsson, \& Tienari, 2013).

Lebih jauh, brand yang dibicarakan oleh publik internal brand dalam bingkai Citizen Public Relations ialah sebuah story atau cerita, oleh sebab story adalah salah satu alat yang paling jitu dalam komunikasi public relations karena pesan akan dapat lebih dipercaya oleh khalayak (Kent, 2015). Oleh karena itu, peran publik internal brand sebagai Citizen Public Relations adalah membagikan cerita soal brand melalui media sosial. Dalam penelitian ini, para mahasiswa Universitas Universal (UVERS) adalah Citizen Public Relations yang dimaksud. Para mahasiswa mendokumentasikan dan membagikan story dalam hidupnya yang terkait dengan brand Universitas Universal (UVERS) melalui media sosial Instagram.

Dalam penelitian ini, Citizen Public Relations dilakukan dengan SoMe Storytelling Branding (Act) oleh para mahasiswa Universitas Universal (UVERS) (Agency) di dalam bingkai computer mediated communication (Scene) melalui media sosial Instagram (Agency) dengan tujuan untuk membangun brand awareness (Purpose). Citizen Public Relations dipaparkan berdasarkan element-elemen teori Grammar of Motives yang dikemukakan oleh Burke.

Para mahasiswa Universitas Universal (UVERS) saat ini sedang hidup dalam setting drama yang sama, mereka hidup di dalam lingkungan Universitas Universal (UVERS) sebagai lakon drama dan berperan sebagai mahasiswa dengan skenarionya masing-masing. Di dalam dramanya masing-masing, keseluruhan hidup para mahasiswa adalah sebuah kesatuan drama dengan berbagai genre di dalamnya. Mahasiswa tidak hanya membicarakan tentang hal-hal yang bersifat bahagia, namun mereka mengungkapkan berbagai genre cerita di media sosial. 
Drama itu sendiri diciptakan melalui konstruksi-konstruksi di antara para mahasiswa, seringkali cerita yang mereka bagikan saling terkait dan berhubungan, namun mereka masih berada di dalam setting drama yang sama membicarakan tentang brand Universitas Universal (UVERS).

Para mahasiswa yang awalnya tidak memiliki tujuan yang jelas ketika bergabung di Universitas Universal (UVERS) akhirnya saling membentuk konstruksi tentang realitas di dalam setting drama bertema brand Universitas Universal (UVERS). Mereka mulai menemukan bahwa kehidupan di Universitas Universal (UVERS) penuh dengan rasa kebersamaan sesuai dengan nilai-nilai peradaban dunia satu keluarga. Selain itu, para mahasiswa juga tertarik membicarakan tentang kegiatan-kegiatan yang dilaksanakan oleh Universitas Universal (UVERS), hingga prestasi-prestasi yang dicapai, dan banyak hal lainnya. Penyebab terjadinya keinginan untuk menceritakan tentang drama di Universitas Universal (UVERS) adalah kenyataan bahwa para mahasiswa hidup di dalam setting drama yang sama.

\section{PENUTUP}

Dalam melakukan ekspresi diri yang identik dengan brand Universitas Universal (UVERS), tentu para mahasiswa didasari oleh berbagai macam motif. Secara disadari atau tidak disadari, motif para mahasiswa dalam melakukan ekspresi tersebut ialah untuk membangun brand awareness. Brand awareness Universitas Universal (UVERS) pada akhirnya berusaha dibentuk dengan SoMe Storytelling Branding, sedangkan para mahasiswa dalam hal ini berperan sebagai Citizen Public Relations yang menceritakan ekspresi dirinya dengan SoMe Storytelling Branding yang terdiri dari Share, Optimize, Manage, dan Engage. Media sosial Instagram dipilih untuk melakukan ekspresi diri yang terkait dengan brand Universitas Universal (UVERS) karena beberapa hal, yaitu surveillance, documentation, creativity, dan coolness. Pada akhirnya brand harus didorong untuk memaksimalkan Citizen Public Relations untuk menjangkau khalayak yang lebih spesifik, karena nilai-nilai brand akan dikomunikasikan oleh pengguna brand itu sendiri. Tentunya semua itu harus dimulai dengan membangkitkan nilai tambah dari brand tersebut.

\section{DAFTAR PUSTAKA}

Alexander, B. (2011). The New Digital Storytelling : Creating Narratives with New Media. California: Praeger.

Asosiasi Penyedia Jasa Internet Indonesia. (2015). Profil Pengguna Internet Indonesia 2014. Jakarta: Asosiasi Penyedia Jasa Internet Indonesia.

Barreda, A. A., Bilgihan, A., Nusair, K., \& Okumus, F. (2015). Generating brand 
awareness in Online Social Networks. Computers in Human Behavior, 1-10.

Barreda, A., Nusair, K., Bilgihan, A., \& Okumus, F. (2013). Developing a brand structure pyramid model for travel-related online social networks. Tourism Review, 68, 49-70.

Burke, K. (1962). A Grammar of Motives. London: University of California Press.

Cawsey, T., \& Rowley, J. (2016). Social media brand building strategies in B2B companies. Marketing Intelligence \& Planning, 34.

Chritton, S. (2012). Personal Branding for Dummies. New Jersey: John Wiley \& Sons Inc.

Grove, S. K., Burns, N., \& Gray, J. R. (2013). The Practice of Nursing Research. Missouri: Elsevier.

Habibi, M. R., Laroche, M., \& Richard, M. O. (2014). The Roles of Brand Community and Community Engagement in Building Brand Trust in Social Media. Computer in Human Behavior, 37, 152-161.

Hartley, J., \& McWilliam, K. (2009). Story Circle : Digital Storytelling Around The World. West Sussex: WileyBlackwell.

Hidayat, M. W. (2016). 3 Media Sosial Favorit Pengguna Internet Indonesia. Retrieved from www.liputan6.com: http://tekno.liputan6.com/read/26340 27/3-media-sosial-favorit-penggunainternet-indonesia

Hootsuite. (2018). Indonesia Digital Landscape 2018. Vancouver: Hootsuite.

Kent, M. L. (2015). The power of storytelling in public relations: Introducing the 20 master plots. Public Relations Review, 41, 480489.
Kesavan, R., Bernacchi, M. D., \& Mascarenhas, O. A. (2013). Word of Mouse: CSR Communication and the Social Media. International Management Review, 9, 59-67.

Kompas.com. (2018). Tahun 2017, Pengguna Internet di Indonesia Mencapai 143,26 Juta Orang. Retrieved from ekonomi.kompas.com:

https://ekonomi.kompas.com/read/20 18/02/19/1611115126/tahun-2017pengguna-internet-di-indonesiamencapai-14326-juta-orang

Konijn, E. A., Utz, S., Tanis, M., \& Barnes, S. B. (2008). How Technology Affects Human Interaction. In E. A. Konijn, S. Uzt, M. Tanis, \& S. B. Barnes (Eds.), Mediated Interpersonal Communication. New York: Routledge.

Konijn, E. A., Utz, S., Tanis, M., \& Barnes, S. B. (2008). Mediated Interpersonal Communication. New York: Routledge.

Laroche, M., Habibi, M. R., \& Richard, M. O. (2013). To be or not to be in social media: How brand loyalty is affected by social media? International Journal of Information Management, 33, 76-82.

Limkangvanmongkol, V. (2015). Brands at The Point of No Return: Understanding \#DRESSFORYOURSELFIE Culture as Post-Postmodern Branding Paradigm. Asia-Pacific Advances in Consumer Research, 11, 51-56.

Lin, T. B., Li, J. Y., Deng, F., \& Lee, L. (2013). Understanding New Media Literacy: An Explorative Theoretical Framework. Educational Technology \& Society, 16, 160-170.

Littlejohn, S. W., \& Foss, K. A. (2009). Encyclopedia of Communication 
Theory. New York: SAGE Publications.

Luttrell, R. (2015). Social Media : How to Engage, Share, and Connect. London: Rowman \& Littlefield.

Malik, M. E., Ghafoor, M. M., Iqbal, H. K., Riaz, U., Hassan, N. U., Mustafa, M., \& Shahbaz, S. (2013). Importance of Brand Awareness and Brand Loyalty in assessing Purchase Intentions of Consumer. International Journal of Business and Social Science, 4, 167171.

Mooij, M. D. (2014). Human and Mediated Communication around The World. New York: Springer International Publishing.

Nofriansyah, D. (2018). Penelitian Kualitatif : Analisis Kinerja Lembaga Pemberdayaan Masyarakat Kelurahan. Yogyakarta: Deepublish.

Pittman, M., \& Reich, B. (2016). Social media and loneliness: Why an Instagram picture may be worth more than a Thousand Twitter words. Computer in Human Behavior, 62, 155-167.

Rokka, J., Karlsson, K., \& Tienari, J. (2013). Balancing acts: managing employees and reputation in social media. Journal of Marketing Management, 30, 802-827.

Salter, B. (2012). Successful Public Relations. London: Hodder Education.

Schummer, T., \& Lukosch, S. (2007). Patterns for Computer-Mediated Interaction. West Sussex: John Wiley \& Sons.

Sheldon, P., \& Bryant, K. (2016). Instagram: Motives for its Use and Relationship to Narcissism and Contextual Age. Computer in Human Behavior, 58, 89-97.
Taylor, S. J., Bogdan, R., \& DeVault, M. L. (2016). Introduction to Qualitative Research Methods. New Jersey: John Wiley and Sons.

Ting, C. T. (2014). A Study of Motives, Usage, Self-presentation and Number of Followers on Instagram. SS Student E-Journal, 3, 1-35.

Tsimonis, G., \& Dimitriadis, S. (2014). Brand Strategies In Social Media. Marketing Intelligence and Planning, 32, 328-344.

Walter, E., \& Gioglio, J. (2014). The Power of Visual Storytelling : How to Use Visuals, Video, and Social Media to Market Your Brand. New York: McGraw Hill.

West, R., \& Turner, L. H. (2010). Introducing Communication Theory. New York: McGraw Hill.

Yusuf, O. (2014, November). Pengguna Internet Indonesia Nomor Enam Dunia. Retrieved from www.kompas.com: http://tekno.kompas.com/read/2014/1 1/24/07430087/Pengguna.Internet.Ind onesia.Nomor.Enam.Dunia 